\title{
FUNGSI GELOMBANG ION HELIUM DALAM REPRESENTASI RUANG POSISI MENGGUNAKAN PERSAMAAN SCHRODINGER
}

\author{
${ }^{1)}$ Muhamad Sukron Makmun, ${ }^{1)}$ Bambang Supriadi, ${ }^{1)}$ Trapsilo Prihandono \\ ${ }^{1)}$ Program Studi Pendidikan Fisika, FKIP, Universitas Jember \\ muhamadsukron32@gmail.com
}

\begin{abstract}
The helium ion is one of the ions included in the hydrogenic atom because it only has a single electron in its outer orbital so that the problem in helium ions can be solved by using the Schrodinger equation approach in spherical coordinates. This research was conducted to examine the helium ion solution in the representation of positional space using the Schrodinger equation at the quantum number $n \leq 2$. The type of research used is basic research, namely the development of theories from the existing ones. The method used is literature study. The results obtained in the form of a radial wave function and a simulation of the radial probability in positional space.
\end{abstract}

Key word: Helium Ion, Schrodinger's Equation, Position Space, Wave Function, Probability

\section{PENDAHULUAN}

Awal munculnya teori fisika kuantum diawali dari beberapa percobaan. Salah satunya mengenai sifat dualisme partikel gelombang yaitu efek fotolistrik dan efek compton yang tidak dapat dijelaskan teori klasik. Dalam percobaan tersebut, partikel dan gelombang tidak dapat dibedakan kapan berperilaku sebagai partikel dan kapan berperilaku sebagai gelombang karena kedua hal tersebut memiliki kaitan yang sangat fundamental. Salah satu perkembangan yang paling berpengaruh saat ini adalah gejala atom hidrogen. Atom Hidrogen merupakan atom yang paling sederhana dan ringan karena hanya terdiri dari sebuah proton dan sebuah elektron pada orbitalnya. Helium merupakan salah satu atom gas mulia yang memiliki 2 proton, 2 neutron, dan 2 elektron dalam orbitalnya. Apabila salah satu elektron dalam atom Helium terionisasi sehingga menjadi ion Helium dan berperilaku seperti atom-atom hidrogenik. Hal ini telah dijelaskan oleh Gautreau dan Savin, 2006: 89 bahwa atom hidrogenik yaitu atom-atom yang memiliki elektron tunggal dalam orbital terluarnya sehingga ion $\mathrm{He}^{+}$ini memiliki perilaku seperti hidrogen dalam seluruh aspeknya, kecuali bahwa nukleusnya memiliki muatan positif $Z e$, dimana $Z$ adalah nomor atomnya. Helium memiliki beberapa manfaat, diantaranya digunakan sebagai pengisi balon udara, digunakan sebagai zat pendingin, dan digunakan untuk membuat udara buatan dimana biasanya dipakai dalam penyelaman dasar laut., Helium juga memiliki beberapa kelebihan yang dinyatakan oleh Alimah dan Sriyono, 2016: 123-124 yaitu dapat digunakan sebagai pendingin karena memiliki karakterisktik sebagai gas ideal atau gas inert, tidak mengalami perubahan sifat fisik maupun kimia pada temperature sangat tinggi, tidak bereaksi pada zat atau gas lain, efektif untuk keperluan perpindahan panas, dan mudah dimampatkan sampai lebih dari $5 \mathrm{MPa}$ Persamaan Schrodinger merupakan persamaan differensial orde dua yang telah ditemukan oleh Erwin Schrodinger dimana persamaan ini memberikan informasi mengenai perilaku gelombang dari suatu partikel seperti fungsi gelombang dan probabilitas. Fungsi 
gelombang pada atom hidrogenik menurut Idris-Bey dan Al-Hashimi (2018) merupakan bentuk kuantitas kompleks yang terdiri dari fungsi radial dan fungsi angular. Hal ini juga dinyatakan oleh Supriadi et al (2018) menyimpulkan bahwa persamaan Schrodinger dapat digunakan untuk mengetahui karakteristik atom dimana dengan menggunakan bilangan kuantum yang berbeda dapat menghasilkan fungsi gelombang yang berbeda pula. Meskipun fungsi gelombang $(\psi)$ dapat memberikan informasi mengenai keadaan suatu sistem setiap saat namun secara fisis belum memiliki makna. Akan tetapi, nilai mutlak dari fungsi gelombang dikuadratkan dan diintergralkan terhadap variabel tertentu, maka hal ini dapat memberikan informasi mengenai makna fisis berupa nilai probabilitas. Nilai probabilitas dari fungsi gelombang radial menyatakan peluang ditemukan suatu partikel dalam posisi $r$ tertentu di dalam atom di mana secara matematis dapat dituliskan $\quad P=\int_{-\infty}^{\infty} r^{2}|R|^{2} d r \quad$ (Warsono, 2007).

Pemecahan permasalahan dalam atom hidrogenik dapat dilakukan dengan menggunakan persamaan schrodinger. Penelitian sebelumnya telah dilakukan oleh Ganesan dan Balaji (2008) mengatakan bahwa untuk menyelesaikan permasalahan atom berelektron tunggal atau bersifat hidrogenik yaitu dengan mengubah koordinat kartesius ke koordinat polar dan butuh pemahaman materi tentang polinom laguerre dan legendre.. Hal ini juga telah dinyatakan oleh penelitian Azis dan Abdullah (2015) menyimpulkan bahwa teknik pendekatan spektral dan pemisahan operator dengan menerapkan fungsi basis Chebyshev dan fungsi basis operatoroperatornya berupa: operator laplacian radian satu dimensi, operator potensial, dan operator sudut dapat menyelesaikan persamaan schrodinger tiga dimensi dalan koordinat bola.

Solusi berupa fungsi gelombang dapat diperoleh dengan menggunakan pendekatan persamaan schrodinger dalam koordinat menggunakan metode separasi variabel dalam keadaan tunak yang dapat dituliskan sebagai berikut:

$\left(\frac{\partial^{2}}{\partial x^{2}}+\frac{\partial^{2}}{\partial y^{2}}+\frac{\partial^{2}}{\partial z^{2}}\right) \psi+\frac{2 m}{\hbar^{2}}(E-V) \psi=0$

Untuk memudahkan penyelesaian dapat digunakan operator laplacian yang dapat diberikan sebagai berikut:

$\nabla^{2}=\frac{1}{r^{2}} \frac{\partial}{\partial r}\left(r^{2} \frac{\partial}{\partial r}\right)+\frac{1}{r^{2} \sin \theta} \frac{\partial}{\partial \theta}\left(\sin \theta \frac{\partial}{\partial \theta}\right)+$

$\frac{1}{r^{2} \sin ^{2} \theta} \frac{\partial}{\partial \phi^{2}}$

Substitusi persamaan (2) ke dalam persamaan (1) diperoleh:

$\frac{\hbar^{2}}{2 m} \frac{1}{r^{2}}\left[\frac{\partial}{\partial r}\left(r^{2} \frac{\partial}{\partial r}\right)+\frac{1}{\sin \theta} \frac{\partial}{\partial \theta}\left(\sin \theta \frac{\partial}{\partial \theta}\right)+\right.$

$\left.\frac{1}{\sin ^{2} \theta} \frac{\partial^{2}}{\partial \phi^{2}}\right] \psi_{(r, \theta, \phi)}+(E-V) \psi_{(r, \theta, \phi)}=0$

Metode separasi variabel dapat dituliskan sebagai berikut:

$\psi_{(r, \theta, \phi)}=R(r) \Theta(\theta) \Phi(\phi)$

Dengan mesubstitusi persamaan (4) ke dalam persamaan (3) diperoleh bentuk sebagai berikut:

$\left[\frac{1}{R} \frac{d}{d r}\left(r^{2} \frac{\partial R}{\partial r}\right)+\frac{2 \mu r^{2}}{\hbar^{2}}(E-V)\right]+$

$\left[\frac{1}{\theta \sin \theta} \frac{d}{d \theta}\left(\sin \theta \frac{d \theta}{d \theta}\right)+\frac{1}{\Phi \sin ^{2} \theta} \frac{d^{2} \Phi}{d \phi^{2}}\right]=0$

Dari persamaan (5) diperoleh tiga bentuk persamaan yaitu persamaan radial yang bergantung pada jari-jari $r$, persamaan polar bergantung pada sudut $\theta$ dan persamaan azimuth bergantung pada sudut $\phi$. Persamaan radial dapat dituliskan sebagai berikut:

$\frac{1}{R} \frac{d}{d r}\left(r^{2} \frac{\partial R}{\partial r}\right)+\frac{2 \mu r^{2}}{\hbar^{2}}(E-V)=0$

Apabila dipilih suatu konstanta pemisah $\beta$ dengan nilai $l(l+1)$ serta dengan mendefiniskan $U(r)=r R(r)$, substitusi ke dalam persamaan (6) diperoleh:

$-\frac{\hbar^{2}}{2 \mu} \frac{d^{2} U(r)}{d r^{2}}+\left(-\frac{1}{4 \pi \varepsilon_{0}} \frac{e^{2}}{r}+\frac{\hbar^{2}}{2 \mu} \frac{l(l+1)}{r^{2}}\right) U(r)=$

$E U(r)$

Sehingga diperoleh solusi radial sebagai berikut:

$R_{n l}=$

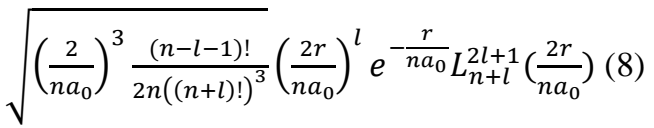

Persamaan polar dapat dituliskan sebagai berikut: 


$$
\frac{1}{\sin \theta} \frac{d}{d \theta}\left(\sin \theta \frac{d \theta}{d \theta}\right)+\left[l(l+1)-\frac{m^{2}}{\sin ^{2} \theta}\right] \theta=0
$$

Solusi dari persamaan (9) diberikan deret polinom legendre terasosiasi $P_{l}^{m}(\cos \theta)$ dapat diberikan sebagai berikut:

$$
\Theta(\theta)=\Theta_{l m}(\theta)=C_{l m} P_{l}^{m}(\cos \theta)
$$

$P_{l} \cos \theta$ merupakan polinomial legendre yang didapatkan dari rumus rodrigues dimana berdasarkan Damanik, 2010: 92 dapat dituliskan sebagai berikut:

$$
P_{l} \cos \theta=\frac{1}{2^{l} l !}\left(\frac{d}{d \cos \theta}\right)^{l}\left(\cos ^{2} \theta-1\right)^{l}(11)
$$

Sehingga diperoleh solusi umum dari persamaan polar sebagai berikut:

$$
\Theta_{l m}(\theta)=(-1)^{\frac{(m+|m|)}{2}} \sqrt{\frac{2 l+1}{2} \frac{(l-|m|) !}{(l+|m|) !}} P_{l}^{m}(\cos \theta)
$$

Persamaan azimuth dapat dituliskan sebagai berikut:

$\frac{d^{2} \Phi}{d \phi^{2}}+m^{2} \Phi=0$

Persamaan (13) merupakan bentuk persamaan differensial orde dua dimana dengan memisalkan $\frac{d^{2}}{d \phi^{2}}=D^{2}$ dan $\frac{d}{d \phi}=D$, maka diperoleh:

$D^{2} \Phi+m^{2} \Phi=0$

Dengan menggunakan rumus abc, maka diperoleh nilai sebagai berikut:

$D= \pm i m$

Kemudian, kedua ruas dikalikan dengan $\Phi$ dan diintegralkan didapatkan:

$$
\Phi(\phi)=A_{m} e^{ \pm i m \phi}
$$

Solusi persamaan schrodinger berupa fungsi dapat diperoleh dengan mengalikan ketiga fungsi yakni fungsi radial, fungsi polar dan fungsi azimuth yakni dapat dituliskan sebagai berikut:

$\psi_{(r, \theta, \phi)}==R(r) \theta(\theta) \Phi(\phi)$

Peluang ditemukan suatu partikel dalam suatu ruang tertentu disebut probabilitas. Bentuk formula dari probabilitas radial berdasarkan Krane, 2012: 208 dapat dituliskan sebagai berikut:

$P=\int_{-\infty}^{\infty} r^{2}|R|^{2} d r$

\section{METODE PENELITIAN}

Penelitian ini merupakan jenis penelitian non eksperimen di mana metode yang digunakan adalah study literature yaitu mengembangkan teori yang sudah ada sebelumnya. Dalam melakukan penelitian ini terdapat beberapa langkahlangkah, diantaranya yaitu persiapan, pengembangan teori, validasi, simulasi, pembahasan, dan kesimpulan.

Tahapan awal berupa persiapan. Pada tahap ini, mempersiapkan beberapa bahan yang dapat dijadikan sebagai sumber informasi guna mendukung penelitian, yaitu berupa buku fisika matematika, fisika atom, fisika modern, fisika kuantum, mekanika kuantum, jurnal mengenai ion Helium dan Persamaan Schrodinger untuk atom berelektron tunggal baik berskala nasional maupun internasional dan artikelartikel yang relevan dengan topik penelitian. Tahap kedua yaitu pengembangan teori Pada yaitu mengembangkan teori yang sudah ada dalam literatur atau buku mengenai Persamaan Schrodinger untuk atom berelektron tunggal. Persamaan Schrodinger atom berelektron tunggal menggunakan persamaan Schrodinger tidak bergantung waktu dalam koordinat bola dimana dalam penyelesaian ini menggunakan metode separasi variabel. Dari separasi variabel tersebut, diperoleh tiga persamaan yaitu persamaan radial yang hanya bergantung jari-jari dan persamaan angular yang hanya bergantung pada sudut. Persamaan angular dibagi menjadi dua yaitu persamaan polar yang hanya bergantung pada sudut $\theta$ dan persamaan azimuth yang hanya bergantung pada sudut $\phi$. Dari persamaan tersebut dapat diperoleh solusi yang berupa fungsi gelombang dimana gabungan dari ketiga persamaan tersebut merupakan solusi atom berelektron tunggal ternormalisasi. Adapun teori yang dikembangkan adalah Persamaan Schrodinger ion Helium dengan bilangan kuantum $n \leq 2$.

Tahapan selanjutnya yang dilakukan adalah validasi alat simulasi di mana peneliti melakukan validasi alat simulasi dari hasil pengembangan teori dimana menggunakan validasi terhadap fungsi gelombang dari atom hidrogen dan 
hasilnya dicocokkan dengan buku literature atau penelitian-penelitian sebelumnya. Selanjutnya, adalah tahapan simulasi/pengambilan data yakni melakukan pengambilan data secara analitik yaitu menentukan fungsi gelombang, probabilitas, dan harga ekspektasi pada ion Helium dengan bilangan kuantum $n \leq 2$ kemudian diambil data secara numerik untuk memperoleh bentuk grafik fungsi radial dan grafik probabilitas radial. Setelah pengambilan data, langkah selanjutnya yaitu pembahasan di mana membahas lebih rinci mengenai perhitungan fungsi gelombang, probabilitas, dan harga ekspektasi pada ion Helium dengan bilangan kuantum $n \leq 2$ dan langkah terakhir berupa kesimpulan yaitu peneliti menyimpulkan hasil dari pembahasan guna menjawab semua rumusan masalah yang ada.

\section{HASIL DAN PEMBAHASAN}

Berdasarkan studi literatur diperoleh data ketetapan untuk mencari jari-jari atom bohr ion Helium $\left({ }_{2}^{4} \mathrm{He}^{+}\right)$ sebagai berikut:
Konstanta planck $\quad(\hbar=1,054 \times$ $10^{-34}$ J.s $)$; massa Proton $\left(m_{p}=\right.$ $\left.1,6726 \times 10^{-27}\right)$; massa elektron $\left(m_{e}=\right.$ $\left.9,1090 \times 10^{-31}\right)$; massa neutron $\left(m_{n}=\right.$ $1,6750 \times 10^{-27}$ ) dan konstanta struktur halus $\quad\left(\alpha=\frac{e^{2}}{4 \pi \varepsilon_{0}}=2,307113707464 \times\right.$ $10^{-28}$ ). Nilai massa tereduksi ion Helium $\left({ }_{2}^{4} \mathrm{He}^{+}\right)$dapat dicari dengan menggunakan persamaan $\mu=\frac{m_{H e^{+} \times m_{e}}}{m_{H e^{+}+m_{e}}}$ dan diperoleh hasil sebesar $9,1077608645938 \times 10^{-31}$ $\mathrm{kg}$. Untuk mencari jari-jari atom bohr ion Helium $\left({ }_{2}^{4} \mathrm{He}^{+}\right)$dengan $\mathrm{Z}=1$ (jumlah elektron) menggunakan massa tereduksi, maka dapat menggunakan persamaan $r=\frac{n^{2} \hbar^{2}}{Z m} \frac{4 \pi \varepsilon_{0}}{e^{2}}=\frac{n^{2} \hbar^{2}}{Z \mu \alpha}$ serta diperoleh hasil sebesar 0,528689400016386 A. Setelah melakukan pengembangan teori atom hidrogenik berupa ion Helium $\left({ }_{2}^{4} \mathrm{He}^{+}\right)$ maka diperoleh hasil simulasi berupa fungsi gelombang ion Helium $\left({ }_{2}^{4} \mathrm{He}^{+}\right)$ dalam representasi ruang posisi pada Tabel (1) sebagai berikut:

Tabel 1. Hasil Simulasi Fungsi Gelombang Ion Helium $\left({ }_{2}^{4} \mathrm{He}^{+}\right)$dalam Representasi Ruang Posisi dengan Bilangan Kuantum $n \leq 2$

\begin{tabular}{|c|c|c|c|c|c|}
\hline$n$ & $L$ & $m$ & $\boldsymbol{R}_{(\boldsymbol{r})}$ & $\boldsymbol{\Theta}_{(\boldsymbol{\theta})}$ & $\Phi_{(\phi)}$ \\
\hline 1 & 0 & 0 & $\frac{2}{a_{0}^{\frac{3}{2}}} e^{-\frac{r}{a_{0}}}$ & $\sqrt{\frac{1}{2}}$ & $\sqrt{\frac{1}{2 \pi}}$ \\
\hline 2 & 0 & 0 & $\frac{1}{\left(2 a_{0}\right)^{\frac{3}{2}}}\left(-\frac{r}{a_{0}}+2\right) e^{-\frac{r}{2 a_{0}}}$ & $\sqrt{\frac{1}{2}}$ & $\sqrt{\frac{1}{2 \pi}}$ \\
\hline 2 & 1 & 0 & $\frac{1}{\left(2 a_{0}\right)^{\frac{3}{2}}} \sqrt{\frac{1}{3}}\left(\frac{r}{a_{0}}\right) e^{-\frac{r}{2 a_{0}}}$ & $\sqrt{\frac{3}{2}}(\cos \theta)$ & $\sqrt{\frac{1}{2 \pi}}$ \\
\hline 2 & 1 & \pm 1 & $\frac{1}{\left(2 a_{0}\right)^{\frac{3}{2}}} \sqrt{\frac{1}{3}}\left(\frac{r}{a_{0}}\right) e^{-\frac{r}{2 a_{0}}}$ & $\pm \frac{1}{2} \sqrt{3}(\sin \theta)$ & $\frac{1}{2 \pi} e^{ \pm i \phi}$ \\
\hline
\end{tabular}


Fungsi Gelombang Ion Helium merupakan solusi persamaan Ion Helium yang dapat diperoleh dengan menggunakan persamaan schrodinger dalam koordinat bola menggunakan metode separasi variabel, di mana berupa kuantitas kompleks yang terdiri dari fungsi radial bergantung pada $r$ dan fungsi angular bergantung pada sudut $(\theta, \varphi)$. Fungsi angular terbagi menjadi dua, yakni fungsi polar dan fungsi azimuth. Secara fisis, fungsi gelombang radial dapat merepresentasikan bahwa elektron dapat ditemukan pada jarak orbit elektron $(r)$ ketika mengorbit pada inti atom (proton) diukur dari pusat atom. Sedangkan fungsi gelombang polar merepresentasikan bentuk orbital elektron berdasarkan sudut teta $(\theta)$ yang memotong bidang $x y$ serta fungsi gelombang azimuth merepresentasikan gerakan elektron berotasi terhadap sudut phi $(\phi)$ secara periodik disekitar sumbu $z$. Solusi Ion Helium dapat diartikan gabungan dari fungsi gelombang radial dan angular yang merepresentasikan keberadaan elektron dan bentuk orbital ketika mengorbit inti.

Fungsi gelombang yang diperoleh terdiri dari fungsi gelombang radial yang bergantung pada bilangan kuantum utama $(n)$ dan bilangan kuantum orbital $(l)$, fungsi gelombang polar bergantung pada bilangan kuantum orbital $(l)$ dan bilangan kuantum magnetik $(m)$ serta fungsi gelombang azimuth yang hanya bergantung pada bilangan kuantum magnetik $(m)$. Ketiga bilangan kuantum tersebut yaitu bilangan kuantum utama (n), bilangan kuantum orbital $(l)$, dan bilangan kuantum magnetik (m) masing-masing merepresentasikan tingkat energi orbital, bentuk orbital, dan orientasi ruang orbital. Selain itu, pada fungsi gelombang radial terdapat polinomial laguerre terasosiasi dan pada fungsi gelombang polar terdapat polinomial legendre terasosiasi.

Dalam mekanika kuantum, meskipun fungsi gelombang dapat memberikan informasi keadaan sistem setiap saat namun hal ini belum sepenuhnya memiliki makna fisis. Akan tetapi, ketika nilai mutlak dari fungsi gelombang dikuadratkan dan diintergralkan terhadap variabel tertentu, maka hal ini dapat memberikan informasi mengenai makna fisis berupa nilai probabilitas di mana secara matematis dapat dituliskan $P=\int_{-\infty}^{\infty} r^{2}|R|^{2} d r$ merupakan jumlah parsial dari $r^{2}|\psi|^{2}$ (Warsono, 2007). Berikut ini merupakan hasil simulasi probabilitas radial elektron ion helium $\left({ }_{2}^{4} \mathrm{He}^{+}\right)$dalam ruang posisi dengan bilangan kuantum $n \leq 2$ disajikan dalam Tabel (2) sebagai berikut:

Tabel 2. Hasil Simulasi Probabilitas Radial Ion Helium $\left({ }_{2}^{4} \mathrm{He}^{+}\right)$dalam Representasi Ruang Posisi dengan Bilangan Kuantum $n \leq 2$

\begin{tabular}{|c|c|c|c|}
\hline \multirow{2}{*}{$R$} & \multirow{2}{*}{$\begin{array}{l}n=1 \\
l=0\end{array}$} & \multicolumn{2}{|c|}{$n=2$} \\
\hline & & $l=0$ & $l=1$ \\
\hline$a_{0}$ & 0.32332358381694 & 0.03431646692496 & 0.00365984682734 \\
\hline $2 a_{0}$ & 0.79852797222392 & 0.05265301734371 & 0.05265301734371 \\
\hline $3 a_{0}$ & 0.93803119558334 & 0.07271585164853 & 0.18473675547623 \\
\hline $4 a_{0}$ & 0.986246032256 & 0.17579625000696 & 0.37116306482013 \\
\hline
\end{tabular}

Untuk mengetahui peluang ditemukan elektrn pada posisi tertentu di dalam atom dapat dilakukan menggunakan nilai probabilitas. Semakin besar bilangan kuantum utama dan bilangan kuantum orbital maka nilai probabilitas semakin kecil. Namun, semakin besar nilai interval posisi partikel $r$ yang diukur dari inti atom maka nilai probabilitas semakin besar karena nilai probabilitas ini berbanding lurus dengan $r^{2}$. Hal ini juga dapat ditunjukkan dalam grafik pada Gambar (1) sebagai berikut: 


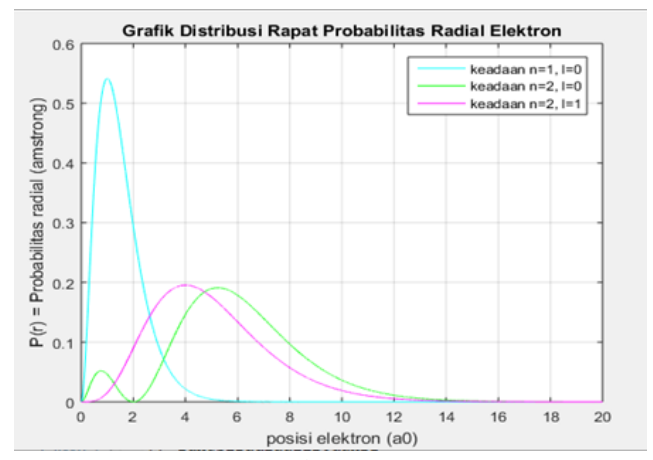

Gambar 1. Hasil Simulasi Grafik Rapat Probabilitas Radial Ion Helium $\left({ }_{2}^{4} \mathrm{He}^{+}\right)$ dalam Representasi Ruang Posisi dengan Bilangan Kuantum $\boldsymbol{n} \leq \mathbf{2}$

Sumbu ordinat menyatakan posisi elektron $(r)$ diukur dari inti atom sedangkan pada sumbu absis menyatakan simpangan $P(r)$ untuk probabilitas. Pada keadaan $n \leq 2$ diperoleh tiga jenis grafik yaitu $n=$ $1, l=0, n=2, l=0$, dan $n=2, l=1$ di mana masing-masing menghasilkan sebuah titik puncak maksimun, dua buah titik puncak maksimum, dan sebuah titik puncak maksimum. nilai tiap-tiap simpangannya tidak ada yang bernilai negatif, sedangkan nilai fungsional pada posisi $r=0$ adalah 0 , artinya peluang untuk menemukan elektron pada posisi 0 yaitu tidak ada. Peluang ditemukan elektron sangat besar dapat ditemukan pada jarak tertinggi yang diukur dari nilai titik puncak yang disebut dengan $r_{\text {max }}$ serta dapat memberikan informasi mengenai ukuran kulit elektron dan ukuran atom (Ohno, 2004: 81). Nilai probabilitas untuk menemukan elektron semakin kecil ketika bilangan kuantum utama semakin besar di mana hal ini ditandai dengan menurunnya nilai simpangan $P(r)$ namun semakin besar interval posisi $r$ maka semakin besar pula nilai probabilitas yang diperoleh.

\section{Saran}

Perlu diadakan penelitian lebih lanjut mengenai atom hidrogenik berupa Ion Helium $\left({ }_{2}^{4} \mathrm{He}^{+}\right)$dengan bilangan kuantum lainnya berupa harga ekspektasi, energy atom, atau ketidakpastian baik posisi maupun momentum dalam ruang posisi.

\section{DAFTAR PUSTAKA}

Alimah, Siti., Sriyono. 2016. Kajian Sistem Pemurnian Helium Reaktor HTGRBerdaya Kecil. Jurnal Pengembangan Energi Nuklir Vol 18 (2): 123-133.

Anderson, E. E. 1982. Introduction to Modern Physics. 1982. Philadelphia: Saunders College Publishing.

Alberty, R. A., Daniels, Farrington. 1987. Kimia Fisika. Jakarta: PT Midas SuryaGrafindo.

Azis, S. A., Abdullah, Z. 2015. Teknik Pemisahan Operator dan Pendekatan Spektral sebagai Solusi Persamaan Schrodinger Bergantung Waktu pada Atom Hidrogen. Jurnal Fisika Unand. Vol 4 (3): 255-262.

Beiser, Arthur. 2003. Concepts of Modern Physics Six Edition. New York: The McGraw-Hill Companies, Inc.

Boas, M. L. 2006. Mathematical Methods in the Physical Sciences Third Edition.United States of America: John Wiley and Sons, Inc.

Damanik, Asan. 2010. Fungsi-Fungsi Khusus. Yogyakarta: Graha Ilmu.

Dong, Xiao., Organov, A. R., Goncharov, A. F. 2014. A Stable Compound of Helium and Sodium at High Pressure. Journal of Nature Chemistry 9 (5):440-445.

Ganesan, L. R., Balaji, M. 2008. Schrodinger Equation for the Hydrogen Atom ASimplified Treatment. Journal of Chemistry. Vol 5 (3): 659-662.

Gasiorowics, S.1996. Quantum Physics Second Edition. Canada: John Wiley \&Sons, Inc. 
Gautreau, W., Savin, W. 2006. Fisika Modern. Jakarta: Erlangga.

Goswami, Amit. 1992. Quantum Mechanics. Dubuque: Wm.C. Brown Publishers.

Griffith, D. J. 2005. Introduction to Quantum Mechanics: Second Edition. ReedCollege, United States of America. Pearson Prentice Hall.

Hanafi, I., Supriadi, B., Handayani, R. D., 2016. Tingkat Energi Atom Helium dengan Pendekatan Model Partikel Bebas (Independent Particle Model). Seminar Nasional Pendidikan 2016. Vol 1. ISSN: 2527-5917.

Hermanto, W. 2016. Fungsi Gelombang Atom Deuterium dengan Pendekatan Persamaan Schrodinger. Jurnal Fisika Prosiding Semnas UNESA. ISBN 978-602-72071-1-0.

Idris-Bey, K., Al-Hashimi, M. H. 2018. Modeling of the Waves Function and ofthe Energy States of Hydrogen Stored in a Spherical Cavity. Advances inScience, Technology and Engineering System Journal. 3(2): 157-163.

Kozlowski, M., Marciak, J. 2010. Modified Schrodinger Equation for Particleswith Mass of the Order of Human Neuron Mass. Neuroquantology. Vol 8(4): 564-570.

Krane, K. 2012. Modern Physics Third Edition. USA: John Wiley \& Son, Inc.

McMahon, David. 2006. Quantum Mechanics Demistified. United States ofAmerica: The McGraw-Hill Companies, Inc.

Ohno, K. 2004. Quantum Chemistry. Tokyo: Permission of Iwanami Shoten.

Purwanto, Agus. 2016. Fisika Kuantum. Surabaya: Gava Media.
Sani, R. A., Kadri, M. 2017. Fisika Kuantum. Jakarta: Bumi Aksara.

Singh, R. B. 2009. Introduction to Modern Physics Volume 1. New Delhi: NewAge International Publisher.

Siregar, R. E. 2019. Mekanika Kuantum Molekul. Jatinangor: Departemen FisikaUniversitas Padjajaran.

Spake, J. J., D. K. Sing., T. M. Evans., V. Bourrier. 2018. Helium in the ErodingAtmosphere of an Exoplanet. Journal of Nature 557(7703): 68-70.

Sriyono., Febrianto. 2011. Desain Konseptual Sistem Pemurnian Helium padaRGTT200K untuk Menjamin Keselamatan Pengoperasiannya. ISSN, 15(3), 132.

Sudiarta, I. W. 2019. Mekanika Kuantum. Mataram: CV. Garuda Ilmu.

Sugiyono, Vani. 2016. Mekanika Kuantum. Yogyakarta: CPAS.

Sukardjo. 2013. Kimia Fisika. Cetakan Ketiga. Jakarta: PT. Rineka Cipta.

Supriadi, B., Ridlo, Z. R., Fuadah, F., Halim, M. A., Maulana, M., Santoso., Y. R.2018. Solution of Spherical Equation in 3 Dimensions forHydrogenAtom with Quantum Numbers $4 \leq n \leq 5$. Journal of Physics:Conf.Series. $1211 \quad$ (2019) 012054, 1-12. doi:10.1088/1742 $6596 / 1211 / 1 / 012054$

Supriyadi., Arkundato, A. 2006. Metode Elemen Hingga untuk Penyelesaian Persamaan Schrodinger Atom Hidrogenik. Jurnal Matematika, Sains, danTeknologi. Vol 7 (1): 1123.

Vaughn, M. T. 2007. Introduction to Mathematical Physics. Germany: Wiley.

Warsono. 2007. Visualisasi Probabilitas Elektron Atom Hidrogenik Dengan GUI(Graphical User Interface) 
MATLAB). Jurnal Pendidikan

Fisika.

Wiyatmo, Yusman. 2008. Fisika Atom.

Yogyakarta: Pustaka Pelajar.

Yusron, M., Firdausi, K. S., Sumariyah. 2007. Review Probabilitas MenemukanElektron dengan Fungsi Gelombang Simetri dan Antisimetri pada Molekul $\mathrm{H}_{2}{ }^{+}$. Jurnal Fisika. Vol 10 (1): 7-12.

Zettili, Nouredine. 2009. Quantum Mechanics Concept and Applications. NewDelhi: John Ram Nagar. 